\title{
THE MICROBIOLOGICAL ASSESSMENT OF DEEP CARIOUS LESIONS AFTER STEP-WISE EXCAVATION AND DIODE LASER CAVITY DISINFECTION (A SIX MONTHS RANDOMIZED CLINICAL TRIAL)
}

\author{
Shahenda Gamal", Eman A Abouauf ** and Hussien A Gomaa***
}

\begin{abstract}
Aim: To assess the antimicrobial effect of diode laser in deep carious lesions after step wise excavation of the tooth using bacteriological assessment method.

Methodology: Thirty permanent molar in fifteen participants with deep occlusal carious lesions were randomly assigned into two groups (15 teeth each) group 1: $\mathrm{Ca}_{2} \mathrm{OH}$ stepwise excavation, group 2: laser disinfection. After cavity preparation, dentin samples were collected at baseline, after immediate disinfection with diode laser device and after six months follow up. Another dentin samples were collected from both $\mathrm{Ca}_{2} \mathrm{OH}$ stepwise excavation and laser disinfection groups. These samples were subjected to microbiological evaluation, Streptococcus mutans on mitis salivarius (MS) agar, and Lactobacilli (LB) on Lactobacillus MRS Agar.
\end{abstract}

Results: The results showed that diode laser had a significant difference from $\mathrm{Ca}_{2} \mathrm{OH}$ stepwise excavation group as it had a significant reduction on Streptococcus mutans and Lactobacillus counts in the laser disinfection group.

Conclusions: The antibacterial effect of diode laser in the deep occlusal cavities was significantly different from $\mathrm{Ca}_{2} \mathrm{OH}$ excavation group. Diode laser disinfection method demonstrated successful clinical measurements when accompanied with step wise technique.

KEYWORDS: Step wise, Deep carious lesions, Microbiological assessment, Diode laser, Disinfection.

\footnotetext{
* Demonstrator at Conservative Dentistry Department, Faculty of Dentistry, Cairo University, Egypt. ** Assistant Professor, Conservative Dentistry Department, Faculty of Dentistry, Cairo University, Cairo, Egypt *** Professor, Conservative Dentistry Department, Faculty of Dentistry, Cairo University, Egypt
} 


\section{INTRODUCTION}

The management of deep carious lesions presents a significant challenge, as during their excavation of the deep carious lesions there are chances for breaking the dentin barrier inducing severe inflammatory reactions in the pulp and may cause pulpal necrosis Singhal et al, (2016).

Deep carious lesions can be managed by using total or partial caries removal techniques. Total caries removal is performed by complete removal of all caries (the central and the peripheral caries biomass) in one visit before definitive restoration. However, this might results in a higher incidence of pulp exposures Hoefler et al. (2016). To minimize the risk of pulp exposure, partial caries removal technique could be used, as it is less invasive and considered as an alternative to the complete caries removal technique which maintains the deeper layer of partially infected carious dentin. The deep layer of infected dentin can be remineralized when covered with a liner, and the tooth definitively restored Singhal et al. (2016). The stepwise excavation technique must be used with vital teeth by removing all carious tissues in two appointments, thus reducing the risk for pulp exposure Opal et al. (2014).

Yet, several microbiological studies had reported the persistence of bacteria in dentin in cavities treated by partial caries removal techniques. Clinical trials with long-term follow up demonstrated cariogenic microorganisms persist under restorations and have an important role in the development of secondary caries. It is reported that numerous bacteria might remain in dentinal tubules after cariostatic-sealed restorations Ersin et al. (2006) Lee et al. (2006) Orhan et al. (2008). The use of an antibacterial agent was found to be very important to reduce the residual bacteria before restoring the cavity. Singhal et al. (2016) Diode laser is able to produce an antibacterial effect on the carious tissue with a minimal amount of thermal disruption to the tooth by different mechanisms including thermal and photodiseruptive effects that are considered the principal reasons for the laser to eliminate the bacteria Parirokh et al. (2007). The application of diode Laser in root canal disinfection showed promising results in effectively reducing the microbial load in infected root canals. Yet no availability of reports till date in regard to cavity disinfection, so it is worth considering testing the effect of using diode laser in cavity disinfection.

\section{MATERIALS AND METHODS}

This study was performed at the outpatient clinic of Conservative Dentistry Department, Faculty of Dentistry and Cairo University. All the procedures performed in this study were in accordance with the ethical standards of the institutional research ethics committee. An informed consent was obtained from all the participants after a detailed explanation of the aim of the study. A protocol was registered in ClinicalTrials.gov (Protocol Registration and Results System (PRS)) database under ID (NCT03298165). The study was performed in a split-mouth design. The study samples were divided into two groups, control group $\left(\mathrm{Ca}(\mathrm{OH})_{2}\right.$ stepwise excavation group) and intervention group (laser disinfection group). From each cavity dentin samples were taken (baseline sample). For $\mathrm{Ca}(\mathrm{OH})_{2}$ stepwise excavation group two dentin samples were taken at baseline and after six months. For laser disinfection group three dentin samples were taken at baseline, after immediate disinfection and after six months. These samples were tested for microbiological analysis.

\section{Sample size calculation}

Based on a previous study by Mohan et al. (2016) the difference in bacterial counts between at least 2 groups is $83.3 \pm 70$. Using power $80 \%$ and $5 \%$ significance level as 12 participants were assigned in each group. Yet the number was increased to a total 15 participants in each group to allow for losses of around $25 \%$. Sample size calculation was achieved using PS: Power and Sample Size Calculation software Version 3.1.2. 
Patients with at least two deep occlusal carious lesions (in any two different quadrants), male or female aged between $18-25$ years in good general health were selected. Eligibility criteria of teeth: The lesions were coronal, active, in the inner half of dentine, absence of sign and symptoms of pulpitis and any periapical lesions.

After local anesthesia application and rubber dam isolation, removal of deep carious tissue was performed following the guidelines published by the International Caries Consensus Collaboration (ICCC) .Caries at the lateral walls of the cavity and at the enamel-dentin junction was completely removed with a sharp, sterile excavator (Maillefer, Dentsply, Switzerland). The central cariogenic biomasses and superficial part of the carious dentin were removed.

Baseline dentin sample collection: Samples were collected from both $\mathrm{Ca}_{2} \mathrm{OH}$ stepwise excavation group and laser disinfection group using another sharp, sterile excavator to avoid contamination from surface dentin Modimi et al. (2016). The dentin samples were immediately transferred to a sterile disposable test tube containing $1.5 \mathrm{ml}$ thioglycollate medium used as a carrier and then transported in an ice box to the microbiology laboratory for processing, within two hours, After incubation the number of bacteria obtained for a given amount of dentin was used to estimate the number of bacteria present in $1 \mathrm{mg}$ dentin (CFU/mg). Lula et al. (2009) and Singhal et al. (2016)

Laser disinfection group (intervention group): In each participant one cavity was disinfected with diode laser device as follows: the cavity was irradiated in contact mode with continuous wave of radiation. The laser light was transferred through a $400 \mu \mathrm{m}$ flexible fiber optic tip by a special hand piece. According to manufactures instructions the fiber optic was inserted inside the cavity with a spiral continuous movement clockwise from the top to the floor and anti-clockwise in the reverse direction Al habeeb et al. (2013). Irradiation time was 15 seconds and repeated three times for 15 seconds interval with contact, pulsed mode and the output power was adjusted at $1.30 \mathrm{~W}$, after using the diode laser, the cavity was rinsed with distilled water. The second sample was taken using another sterile, sharp excavator Mohan et al. (2016). Then the cavity were restored and sealed with glass ionomer restoration (Equia ${ }^{\mathrm{TM}}$ Fil), the material was applied according to manufacturer instructions.

$\mathrm{Ca}(\mathrm{OH})_{2}$ stepwise excavation group (control group): After taking the baseline dentin sample from the prepared cavity, the bottom of the cavity was lined with a calcium hydroxide-containing base material (Urbical, Promedica, Germany). The cavity was restored and sealed with glass ionomer restoration (Equia ${ }^{\mathrm{TM}}$ Fil) same as the laser disinfection group Bjørndal et al. (2010) Firmino et al. (2018).

Stepwise excavation procedure: After six months period, the integrity of the intermediate restoration was checked up, the rubber dam application, the transitional glass ionomer filling and calcium hydroxide liner were totally removed from both cavities using the same tools used in the first visit, another dentine sample was taken for microbiological study Orhan et al. (2008). Stepwise excavation for hardened dentine layer and removal of the residual carious tissue was performed using a sharp excavator. The excavation end point was the detection of firm dentine at the pulpal floor using a sharp dental explorer. The cavity was cleaned using wet cotton, dried and then finally restored by resin composite restoration Singhal et al.(2016) Firmino et al. (2018).

Microbiological Analysis: Singhal et al. (2016) Firmino et al. (2018)

The sterilized test tubes containing the dentin samples were shaken in a vortex for $30 \mathrm{~s}$ to disperse bacterial aggregates and decimal dilutions were then prepared in sterile saline $(0.9 \% \mathrm{NaCl})$. Next, 
$50 \mu \mathrm{l}$ aliquots of each dilution were spread using micropipette onto the following solid media and spread on the surface of the agar using sterile glass rod to give homogenous bacterial growth. Mitis salivarius agar (MSA) (HiMedia Laboratories Pvt. Ltd.india) was used for Streptococcus sp. count and MSA was supplemented with $20 \%$ sucrose, 0.2 units $/ \mathrm{ml}$ bacitracin, and $1 \%$ potassium tellurite (mitis-salivarius bacitracin [MSB]) for mutans streptococci count. The MSA plates were incubated in an atmosphere of $5 \% \mathrm{CO}_{2}$ inside candle jar for 48 h. Lactobacillus MRS Agar (HiMedia Laboratories Pvt. Ltd India) was used for lactobacillus count. The MRS plates were incubated anaerobically at $37^{\circ} \mathrm{C}$ for 24-72 hours in a $\mathrm{CO}_{2}$ incubator. After incubation, the numbers of colony forming units (CFUs) were performed

\section{Statistical analysis}

Data explored for normality using KolmogorovSmirnov test. Independent t-test used to compare between each 2 groups for Log CFU/ml. Dependent t-test used compared between before and after Laser application for each group. Repeated ANOVA used to compare between follow-up periods for intervention group followed by pairwise with Bonferroni correction. Significant level was set at $0.05(\alpha=0.05)$. Statistical analysis was done using Statistical Package for the Social Sciences (IBM SPSS Statistics for Windows, Version 23.0. Armonk, NY: IBM Corp

\section{RESULTS}

From a total of 15 enrolled participants, two were subsequently excluded from the analysis, (one left the trial due to the military service and another not answering the phone), thus the final sample consisted of 13 patients, 13 teeth in the $\mathrm{Ca}(\mathrm{OH})_{2}$ stepwise excavation group and 13 teeth in the laser disinfection group. During the follow-up period, no patients had signs or symptoms consistent with pulp alteration. Results of the current study revealed that on comparing streptococcus mutans $\log (\mathrm{CFU} / \mathrm{ml})$ and lactobacilli $\log (\mathrm{CFU} / \mathrm{ml})$ at different follow up intervals; baseline, immediate laser disinfection and after six months of laser disinfection group there was a significant reduction in the $\log \mathrm{CFU} / \mathrm{ml}$ at mean and SD $(2.02 \pm 0.19),(1.34 \pm 0.21),(1.05 \pm 0.41)$ respectively resulted at $\mathrm{p} \leq 0.001$.

TABLE (1) Mean and standard deviation (SD) for $\log \mathrm{CFU} / \mathrm{ml}$ at different follow-up periods for the laser disinfection group.

\begin{tabular}{|c|c|c|c|c|c|c|c|}
\hline \multirow{2}{*}{$\begin{array}{c}\text { Laser } \\
\text { disinfection }\end{array}$} & \multicolumn{2}{|c|}{ Baseline } & \multicolumn{2}{c|}{$\begin{array}{c}\text { After } \\
\text { immediate }\end{array}$} & \multicolumn{2}{c|}{$\begin{array}{c}\text { After six } \\
\text { months }\end{array}$} & \multirow{2}{*}{ P-value } \\
\cline { 2 - 9 } & Mean & SD & Mean & SD & Mean & SD & \\
\cline { 2 - 8 } & $2.02^{\mathrm{a}}$ & 0.19 & $1.34^{\mathrm{b}}$ & 0.21 & $1.05^{\mathrm{c}}$ & 0.41 & $\leq 0.001^{*}$ \\
\hline
\end{tabular}

Different letter within column indicates significant difference

*=significant, $N S=$ Non-significant

Comparing streptococcus mutans log $(\mathrm{CFU} / \mathrm{ml})$ and lactobacilli $\log (\mathrm{CFU} / \mathrm{ml})$ at different follow up intervals; baseline and after six months of both $\mathrm{Ca}(\mathrm{OH})_{2}$ stepwise excavation and laser disinfection group there was a significant reduction in the log $\mathrm{CFU} / \mathrm{ml}$ at mean and $S D(1.96 \pm 0.19),(1.77 \pm 0.10)$ for $\mathrm{Ca}(\mathrm{OH})_{2}$ stepwise excavation group resulted at $\mathrm{p}=0.008$ and $(2.02 \pm 0.19),(1.05 \pm 0.41)$ for laser intervention group resulted at $\mathrm{p} \leq 0.001$.

Table 2: Mean and standard deviation (SD) for Log $\mathrm{CFU} / \mathrm{ml}$ of $\mathrm{Ca}(\mathrm{OH})_{2}$ stepwise excavation and laser disinfection groups at different follow-up periods.

\begin{tabular}{|c|c|c|c|c|c|}
\hline Group & \multicolumn{2}{|c|}{$\begin{array}{c}\mathrm{Ca}(\mathrm{OH})_{2} \text { stepwise } \\
\text { excavation }\end{array}$} & \multicolumn{2}{|c|}{$\begin{array}{c}\text { laser } \\
\text { disinfection }\end{array}$} & \multirow{2}{*}{ p-value } \\
\cline { 2 - 5 } & Mean & SD & Mean & SD & \\
\hline Baseline & 1.96 & 0.19 & 2.02 & 0.19 & $0.401 \mathrm{NS}$ \\
\hline Six months & 1.77 & 0.10 & 1.05 & 0.41 & $\leq 0.001^{*}$ \\
\hline P-value & \multicolumn{2}{|c|}{$0.008^{*}$} & \multicolumn{2}{|c|}{$\leq 0.001^{*}$} & \\
\hline
\end{tabular}

$*=$ significant, $N S=$ Non-significant 


\section{DISCUSSION}

Diode Laser can be used for a multiple dental procedures, predominantly soft tissue procedures such as gingivectomy, pulpotomy, frenectomy, and some hard tissue procedures such as root canal disinfection and tooth whitening Pirnat (2007) and Maturo et al. (2013). In the diode laser disinfection group, the irradiation technique was used in cycles; each cycle consisted of 15 seconds with 15 second intervals and three cycles of irradiation were applied. This technique was recommended because streptococcus mutans and lactobacillus are a gram-positive, non-motile, short-rod facultative anaerobe. They are relatively resistant to laser irradiation because of their tough cell wall, so they required more than one cycle of laser irradiation to reach the deeper layer and disrupt it Lee et al. (2006). The output power was adjusted at $1.30 \mathrm{~W}$, according to a previous pilot study; it was the most efficient to disinfect the cavity while avoiding thermal effect to the pulp, as the thermal effect is the most important to be considered during laser applications. This was suggested by $\mathbf{A l}$ habeeb et al. (2013). The prime benefit of a pulsed mode will be the capacity of the target tissue to cool between successive pulses. The continuous mode is generally the fastest way to ablate tissues but heat can build up and cause collateral damage to the target and adjacent tissues Prinat (2007). The laser beam was delivered through a flexible $400 \mu \mathrm{m}$ optic fiber with a spiral continuous movement clockwise from the top to the floor and anti-clockwise in the reverse direction. This improves the distribution of the laser lig ht inside the cavity also avoid excessive heat generation and carbonization in the internal cavity surface Al habeeb et al. (2013).

On the other hand, $\mathrm{Ca}(\mathrm{OH})_{2}$ stepwise excavation acts as follows; the first phase inactivates caries progression and allows the occurrence of physiological reactions in the pulp-dentine complex represented by dentine sclerosis and tertiary dentine formation. Over time this makes carious dentin easier to remove without exposing the pulp at the final excavation. Such reactions might also be enhanced by placing a calcium hydroxide compound on the remaining carious dentin. Calcium hydroxide is used for lining specific areas of deep cavities or for direct pulp capping. Initially it is bactericidal then bacteriostatic, it stimulates the formation of reparative dentin as its high $\mathrm{pH}$ creates an alkaline environment stimulates fibroblasts and increase the availability of calcium ions Maltz et al. (2002) Pinto et al. (2006) Bjørndal et al. (2010) Sangwan et al. (2013) Song et al. (2017).

A transitional restoration was chosen to be high viscosity glass ionomer restoration. It has been usually used with stepwise excavation techniques due to its clinical efficiency as chemical adhesion, biocompatibility, bioactive, releasing of fluoride, and nearly coefficient of linear thermal expansion and modulus of elasticity to that of the tooth structure Corralo and Maltz (2013) MenezesSilva et al. (2019).

The results of this study showed that when comparing bacterial count of the laser disinfection group at the baseline and after immediate disinfection there was a significant difference in reduction of the bacterial count. Lee et al. (2006) Parirokh et al. (2007) Gordon et al. (2007) Alhabeeb et al. (2013) Mohan et al. (2016) Arslan et al. (2019) support this result. They explained that there are different mechanisms regarding the antibacterial effect of diode laser. The principal reasons are the thermal and photodiseruptive effects of diode laser, as it causes lethal damage to bacterial cells due to destruction of the cell wall integrity and denaturation of proteins: as the cellular protein is highly sensitive to the thermal changes leading to cell death. Also the possibility of occluding the dentinal tubules resulting from thermal effect of laser on dentin cells leads to the entrapping of the invading microorganisms and reduction of the 
dentinal fluid as a source of nutrition. Another fact was that the diode laser beam is highly absorbed by water more than dental tissues when compared to other types of laser. This characteristic means greater penetration of laser beam through the cavity with little interaction on the dentin, making it to act on the microorganisms present inside the dentinal tubules Safan et al. (2014). It was observed that there was a dramatic reduction of the bacterial count after six months of laser disinfection group, this could be due to the antibacterial effect of diode laser which decrease bacterial count. Moreover, the sealing of the cavity with cariostatic filling material changed the ecology and restricted neutral supply from oral cavity to the microorganism Pinto et al. (2006) Orhan et al. (2008) Firmino et al. (2018). Comparing the mean values of the Streptococcus mutans and Lactobacillus count after $\mathrm{Ca}(\mathrm{OH})_{2}$ step wise excavation group; at the baseline and after six months period, the six months showed reduction of bacterial count more than that reported at base line with a significant difference $\mathrm{p}=0.008$. This result was in agreement with Bjørndal and Larsen (2000) Maltz et al. (2002) Paddick et al. (2005) Orhan et al. (2008) Lula et al. (2009) Maltz et al. (2012) Firmino et al. (2018

On the other hand some clinical studies showed that there was no need for re- entry to remove the residual dentine, as the second removal step may increase risks of pulpal exposure in addition to the added cost, time and effort. Schwendicke et al. (2016) El hennawy et al. (2018) Bjørndal et al. (2019) Innes and Schwendicke (2019). Stepwise excavation technique in deep lesions is a promising alternative for preserving pulp vitality as it showing clinical success even after several years Hoefler et al. (2016) Bjørndal et al. (2017) Firmino et al. (2018).

An obstacle to using diode laser in daily dental practice is its high cost, however there are many advantageous properties supported by the current study that using such method could be a promising step into preserving the pulp vitality and the remaining tooth structure. Hopefully in the future, laser disinfection could be more accessible to the dental practice

\section{CONCLUSION}

Lactobacillus being the driving force in the spread of deep carious lesion could be better controlled by diode laser disinfection. Step wise technique proved to be clinically efficient technique for management of deep carious lesion. Diode laser disinfection method demonstrated a successful clinical measurement when accompanied by step wise technique.

\section{REFERENCES}

- Al-habeeb, A., Nayif, M. and Taha, M. Y. (2013): Antibacterial effects of diode laser and chlorhexidine gluconate on streptococcus mutans in coronal cavity. Web med Central.

- Arslan, I., Baygin, O., Bayram, G., Akyol, R. and Tuzuner, T. (2019): Effects of various agents and laser systems on antibacterial activity and microtensile bond strength when used for cavity disinfection. Journal of Dental Lasers, 13(1), 12 .

- $\quad$ Bjørndal L and Larsen T (2000): Changes in the cultivable flora in deep carious lesions following a stepwise excavation procedure. Caries Res 34:502-508

- $\quad$ Bjørndal, L, C Reit, G Bruun, M Markvart, M Kjældgaard, P Na, M Thordrup, Peggy Näsman, Bente Nyvad, and Helena Fransson. (2010): Treatment of Deep Caries Lesions in Adults : Randomized Clinical Trials Comparing Stepwise vs . Direct Complete Excavation, and Direct Pulp Capping vs . Partial Pulpotomy. European journal of oral sciences, 118(3), 290-297

- Bjørndal L, Fransson H, and Bruun G et al. (2017): Randomized clinical trials on deep carious lesions: 5-year follow-up. Journal of Dental Research 96, 747-53

- $\quad$ Bjørndal, L., Simon, S., Tomson, P. L. and Duncan, H. F. (2019): Management of deep caries and the exposed pulp. International endodontic journal, 52(7), 949-97 
- Corralo, D. J., and Maltz, M. (2013): Clinical and ultrastructural effects of different liners/restorative materials on deep carious dentin: a randomized clinical trial. Caries research, 47(3), 243-250.

- Elhennawy, K., Finke, C., Paris, S., Reda, S., JostBrinkmann, P. G. and Schwendicke, F. (2018): Selective vs stepwise removal of deep carious lesions in primary molars: 12-months results of a randomized controlled pilot trial. Journal of dentistry, 77, 72-77.

- $\quad$ Ersin, N. K., Uzel, A., Aykut, A., Candan, U. and Eronat, C. (2006): Inhibition of cultivable bacteria by chlorhexidine treatment of dentin lesions treated with the ART technique. Caries research, 40(2), 172-177.

- $\quad$ Firmino, L., Soares, V. K., Damé-Teixeira, N., Parolo, C. C. F., and Maltz, M. (2018): Microbial load after selective and complete caries removal in permanent molars: a randomized clinical trial. Brazilian dental journal, 29(3), 290-295.

- Gordon, W., Atabakhsh, V. A., Meza, F., Doms, A., Nissan, R., Rizoiu, I., and Stevens, R. H. (2007): The antimicrobial efficacy of the erbium, chromium: yttrium-scandiumgallium-garnet laser with radial emitting tips on root canal dentin walls infected with Enterococcus faecalis. The Journal of the American Dental Association, 138(7), 9921002.

- Hoefler, V., Nagaoka, H., and Miller, C. S. (2016): Longterm survival and vitality outcomes of permanent teeth following deep caries treatment with step-wise and partialcaries-removal: a systematic review. Journal of dentistry, 54,25

- Innes, N., and Schwendicke, F. (2019): Treatment options for carious tissue removal. Clinical Dentistry Reviewed, $3(1), 3$.

- $\quad$ Lee, B. S., Lin, Y. W., Chia, J. S., Hsieh, T. T., Chen, M. H., Lin, C. P., and Lan, W. H. (2006): Bactericidal effects of diode laser on Streptococcus mutans after irradiation through different thickness of dentin. Lasers in Surgery and Medicine: The Official Journal of the American Society for Laser Medicine and Surgery, 38(1), 62-69.

- Lula, E. C., Monteiro-Neto, V., Alves, C. M., and Ribeiro, C. C. (2009): Microbiological analysis after complete or partial removal of carious dentin in primary teeth: a randomized clinical trial. Caries Research, 43(5), 354-358.

- Maltz, M., de Oliveira, E. F., Fontanella, V., and Bianchi, R. (2002): A clinical, microbiologic, and radiographic study of deep caries lesions after incomplete caries removal. Quintessence international, 33(2).

- $\quad$ Maturo, P., Perugia, C., and Docimo, R. (2013): Versatility of an $810 \mathrm{~nm}$ diode laser in pediatric dentistry. International Journal Clin Dent 2013; 6:161-72

- Menezes-Silva, R., Velasco, S. R. M., Bastos, R. S., Molina, G., Honório, H. M., Frencken, J. E., and Navarro, M. F. L. (2019): Randomized clinical trial of class II restoration in permanent teeth comparing ART with composite resin after 12 months. Clinical oral investigations, 23(9), 36233635 .

- Modimi, K. V, Siddaiah, S. B., Chikkanarasaiah, N., Rucha, V., Abubakar, S. B., Dinraj, K., and Syed, S. S. (2016): Microbiological assessment of carious dentine using chemomechanical caries removal and conventional hand excavation in primary and permanent teeth: a clinical study. Journal of International Oral Health, 8(7), 760-766.

- Mohan, P. U., Uloopi, K. S., Vinay, C., and Rao, R. C. (2016): In vivo comparison of cavity disinfection efficacy with APF gel, Propolis, Diode Laser, and 2\% chlorhexidine in primary teeth. Contemporary clinical dentistry, 7(1), 45.

- Opal S, Garg S, Dhindsa A, and Taluja T (2014): Minimally invasive clinical approach in indirect pulp therapy and healing of deep carious lesions. The Journal of Clinical Pediatric Dentistry 38(3): 185-92

- $\quad$ Orhan, A. I., Oz, F. T., Ozcelik, B., and Orhan, K. (2008): A clinical and microbiological comparative study of deep carious lesion treatment in deciduous and young permanent molars. Clinical oral investigations, 12(4), 369-378.

- Parirokh, M., Eghbal, M. J., Asgary, S., Ghoddusi, J., Stowe, S., Forghani, F., and Shahravan, A. (2007): Effect of $810 \mathrm{~nm}$ diode laser irradiation on root canal walls after smear layer removal: A scanning electron microscope study. Iranian endodontic journal, 2(2), 37.

- $\quad$ Pinto AS, de Araujo FB, Franzon R, Figueiredo MC, Henz S, Garcia-Godoy F, and Maltz M (2006): Clinical and microbiological effect of calcium hydroxide protection in indirect pulp capping in primary teeth. Am J Dent 19:382386.

- $\quad$ Pirnat, S. (2007): Versatility of an $810 \mathrm{~nm}$ diode laser in dentistry: An overview. Journal of Laser Health Academy, 4(2), 1-9.

- $\quad$ Safan, A., Youssef, T., Zaazou, M. H., El-Moez, S. I. A., El-Shinawy, H., and Sadony, D. M. (2014): Antibacterial 
effect of silver and gold nanoparticles and diode laser against Lactobacillus acidophilus bacteria. International Journal Advance Research, 2(8), 34-38

- Sangwan, P., Sangwan, A., Duhan, J., and Rohilla, A. (2013): Tertiary dentinogenesis with calcium hydroxide: a review of propose mechanisms. International endodontic journal, 46(1), 3-19.

- Schwendicke, F. and Göstemeyer, G. (2016): Understanding dentists' management of deep carious lesions in permanent teeth: a systematic review and metaanalysis. Implementation Science, 11(1), 142.
- Singhal, D. K., Acharya, S., and Thakur, A. S. (2016): Microbiological analysis after complete or partial removal of carious dentin using two different techniques in primary teeth: A randomized clinical trial. Dental research journal, 13(1), 30 .

- $\quad$ Song, M., Yu, B., Kim, S., Hayashi, M., Smith, C., Sohn, S. and Kim, R. H. (2017): Clinical and molecular perspectives of reparative dentin formation: Lessons learned from pulpcapping materials and the emerging roles of calcium. Dental Clinics, 61(1), 93-110. 